Article

\title{
Torrefaction of Coffee Husk Flour for the Development of Injection-Molded Green Composite Pieces of Polylactide with High Sustainability
}

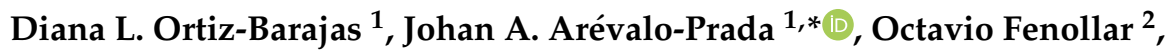 \\ Yesid J. Rueda-Ordóñez ${ }^{1}$ and Sergio Torres-Giner ${ }^{3, *(\mathbb{D})}$ \\ 1 Grupo de Investigación en Energía y Medio Ambiente (GIEMA), Universidad Industrial de Santander (UIS), \\ 680002 Bucaramanga, Colombia; diana.ortiz10@correo.uis.edu.co (D.L.O.-B.); yjruedao@uis.edu.co (Y.J.R.-O.) \\ 2 Technological Institute of Materials (ITM), Universitat Politècnica de València (UPV), \\ Plaza Ferrándiz y Carbonell 1, 03801 Alcoy, Spain; ocfegi@epsa.upv.es \\ 3 Novel Materials and Nanotechnology Group, Institute of Agrochemistry and Food Technology (IATA), \\ Spanish National Research Council (CSIC), Calle Catedrático Agustín Escardino Benlloch 7, \\ 46980 Paterna, Spain \\ * Correspondence: johan.arevalo@correo.uis.edu.co (J.A.A.-P.); storresginer@iata.csic.es (S.T.-G.); \\ Tel.: +57-315-443-3621 (J.A.A.-P.); +34-963-900-022 (S.T.-G.)
}

Received: 29 August 2020; Accepted: 15 September 2020; Published: 17 September 2020

Featured Application: Green composite pieces of polylactide (PLA) containing $20 \mathrm{wt} \%$ of coffee waste derived filler can be applied for rigid packaging, such as food trays and containers, beverage cups, and food contact disposables, such as cutlery and plates.

\begin{abstract}
Coffee husk, a major lignocellulosic waste derived from the coffee industry, was first ground into flour of fine particles of approximately $90 \mu \mathrm{m}$ and then torrefied at $250{ }^{\circ} \mathrm{C}$ to make it more thermally stable and compatible with biopolymers. The resultant torrefied coffee husk flour (TCHF) was thereafter melt-compounded with polylactide (PLA) in contents from 20 to $50 \mathrm{wt} \%$ and the extruded green composite pellets were shaped by injection molding into pieces and characterized. Although the incorporation of TCHF reduced the ductility and toughness of PLA, filler contents of $20 \mathrm{wt} \%$ successfully yielded pieces with balanced mechanical properties in both tensile and flexural conditions and improved hardness. Contents of up to $30 \mathrm{wt} \%$ of TCHF also induced a nucleating effect that favored the formation of crystals of PLA, whereas the thermal degradation of the biopolyester was delayed by more than $7^{\circ} \mathrm{C}$. Furthermore, the PLA/TCHF pieces showed higher thermomechanical resistance and their softening point increased up to nearly $60^{\circ} \mathrm{C}$. Therefore, highly sustainable pieces were developed through the valorization of large amounts of coffee waste subjected to torrefaction. In the Circular Bioeconomy framework, these novel green composites can be used in the design of compostable rigid packaging and food contact disposables.
\end{abstract}

Keywords: PLA; coffee husk; torrefaction; green composites; waste valorization; Circular Bioeconomy

\section{Introduction}

Valorization of food processing by-products and agricultural waste is acquiring increasing importance due to the high interest in the development of novel sustainable materials as part of the Circular Bioeconomy framework [1,2]. Agro-food wastes, such as flax fibers [3,4], rice husk [5], jute fibers [6,7], almond husk [8,9], walnut husk [10], orange peel [11], coconut fibers [12] or sisal fibers [13], represent examples of recently explored fillers to be incorporated into biopolymer matrices. The resultant green composites can successfully show technological advantages over 
conventional petroleum derived polymer composites, including cost reduction, lower density, no toxicity, balanced mechanical properties and, more importantly, lower environmental impact [14,15]. However, natural fillers also have some disadvantages, such as lower thermal stability and higher moisture absorption $[15,16]$. Therefore, the optimal amount of filler content for a given polymer matrix and the specific target application must be carefully determined. In addition, different compatibilization strategies, such as fillers modifications and/or the use of multi-functional additives, can be used [17].

Coffee is considered by many to be the most popular hot beverage in the world, being consumed for its refreshing and stimulating properties. It is the most consumed drink after water and tea, the second largest traded commodity after petroleum, and probably the most essential agricultural commodity [18]. Coffee beans are one of the most important tropical products, being cultivated primarily in the "the coffee belt" area between $25^{\circ} \mathrm{N}$ and $25^{\circ} \mathrm{S}$ latitude [19]. Brazil, Vietnam, Indonesia, Colombia, and India are the global leaders in production of green coffee beans. Annual production of coffee increased from 140 to 152 million bags of $60 \mathrm{~kg}$ in 2010 [20]. However, the 'fruit-to-cup' transformation of coffee beans generates huge quantities of by-products and wastes, such as leaf, flower, cherry as well as coffee silver skin (CSS), coffee husks, and spent coffee ground (SCG) [21,22]. In particular, approximately $68 \mathrm{~kg}$ of green coffee waste are produced per $100 \mathrm{~kg}$ of fresh coffee, in which 50 and $18 \mathrm{~kg}$ correspond to coffee pulp and husk, respectively [23]. The CSS, which is the main by-product of the roasting process, includes dietary fiber (50-60 wt\%) protein (16-19 wt\%), fat (1.56-3.28 $\mathrm{wt} \%$ ), and ash (7 wt\%) [24]. The main current value-adding applications include biofuel [25] or energy purposes [26], fertilizer production [27], dietary fiber [28], and bioactive compound extraction [29]. However, animal feeding is limited by the presence of caffeine and tannins, phenolic compounds that show anti-nutritional properties [30]. Furthermore, chlorogenic acid is phytotoxic when used as a plant fertilizer [31]. Therefore, the valorization of coffee by-products is a technological challenge and new added value applications are pursued.

In a Circular Bioeconomy context, the use of coffee husk in the form of flour as possible reinforcing filler in polymer composites can represent a sustainable method of valorization [32]. Some previous studies have incorporated different fillers derived from by-products of the coffee industry into biopolymer materials. Some examples include the production of biodegradable compounds for food packaging applications using poly(butylene adipate-co-terephthalate) (PBAT) and coffee grounds [33], the reinforcement of high-density polyethylene (HDPE) by coffee hull $(\mathrm{CH})$ [34] or sustainable composites of polypropylene (PP) and ground coffee powder for use as wood plastic composites (WPCs) [35]. However, given the origin of such solid residue, the typical content of total carbohydrates (58-85 wt\%) and moisture (up to $15 \mathrm{wt} \%$ ) in coffee husk is high, with reported contents of cellulose, hemi-cellulose, and lignin of 43,7 , and $9 \mathrm{wt} \%$ on a dry basis, respectively [36]. Although such levels are low or at most similar to other lignocellulosic residues [37], this fact limits its application for polymer composites. In this regard, torrefaction of biomass can represent a novel strategy to not only enhance its performance for renewable energy applications in terms of grindability, higher calorific value, long-term storage, and handling, but also improve its affinity with polymer matrices [38]. Torrefaction is a mild form of pyrolysis performed at temperatures ranging from 200 to $300{ }^{\circ} \mathrm{C}$ under atmospheric pressure and in the absence of oxygen [39]. During this thermochemical treatment, the water contained in cellulose, hemicellulose, and lignin, as well as superfluous volatiles, are released, typically around $20 \mathrm{wt} \%$, resulting in a relatively dry product that reduces or eliminates its potential for organic decomposition and is also more hydrophobic [40].

Among the biopolymers, polylactide (PLA) currently has a key position in the bioplastic market for both technical and commodity products [41]. PLA is a thermoplastic biopolyester that can be obtained from natural and renewable sources such as cornstarch or cassava and its articles can be compostable in industrial conditions [42]. It is mainly used in compostable food packaging and disposables, biomedical devices and, more recently, 3D printing applications [43-45]. In this study, coffee husk flour (CHF) was first torrefied and then incorporated into PLA by twin-screw extrusion (TSE) and the resultant compounded pellets were shaped into pieces by injection molding. Different torrefied coffee 
husk flour (TCHF) contents were incorporated into PLA and the mechanical and thermal properties were determined to analyze the influence of the coffee waste derived lignocellulosic filler on the final performance of the green composite pieces and ascertain their potential for sustainable packaging and disposables.

\section{Materials and Methods}

\subsection{Materials}

PLA biopolymer commercial grade Ingeo ${ }^{\mathrm{TM}}$ 3001D was supplied in pellet form by NatureWorks LLC (Minnesota, MN, USA). This grade corresponds to a poly(D,L-lactide) (PDLLA) of high optical purity in L-lactic acid isomer, with $1.4 \pm 0.2 \%$ of D-lactic acid fraction [46]. The number- and weight-average molecular weights were found to be $\mathrm{M}_{\mathrm{n}}=90.5 \mathrm{kD}$ and $\mathrm{M}_{\mathrm{W}}=158.3 \mathrm{kD}$ by gel permeation chromatography (GPC), which gives a polydispersity index ( $\left.\mathrm{PDI}=\mathrm{M}_{\mathrm{W}} / \mathrm{M}_{\mathrm{n}}\right)$ of 1.75 [47]. It is also characterized by a density of $1.24 \mathrm{~g} / \mathrm{cm}^{3}$ following the American Society for Testing and Materials (ASTM) method D792 and a melt flow rate (MFR) of $22 \mathrm{~g} / 10 \mathrm{~min}$, measured at $210^{\circ} \mathrm{C}$ and $2.16 \mathrm{~kg}$, according to the ASTM method D1238, which makes it feasible for injection molding.

Coffee husks were separated from the previously natural dried grains by a threshing process. The husks were obtained from a coffee crop located at $1390 \mathrm{~m}$ above sea level in the San José de Motoso district of Girón in Santander, Colombia, and were dried in a laboratory oven at $105^{\circ} \mathrm{C}$ for $24 \mathrm{~h}$ to remove moisture. Afterwards, the dried husks were milled at a speed of $8000 \mathrm{rpm}$ using a ZM 200 centrifugal mill from Retsch (Düsseldorf, Germany) and finally sieved with a 250- $\mu \mathrm{m}$ mesh filter to the size of 110 microns to obtain the so-called CHF (see Figure 1).
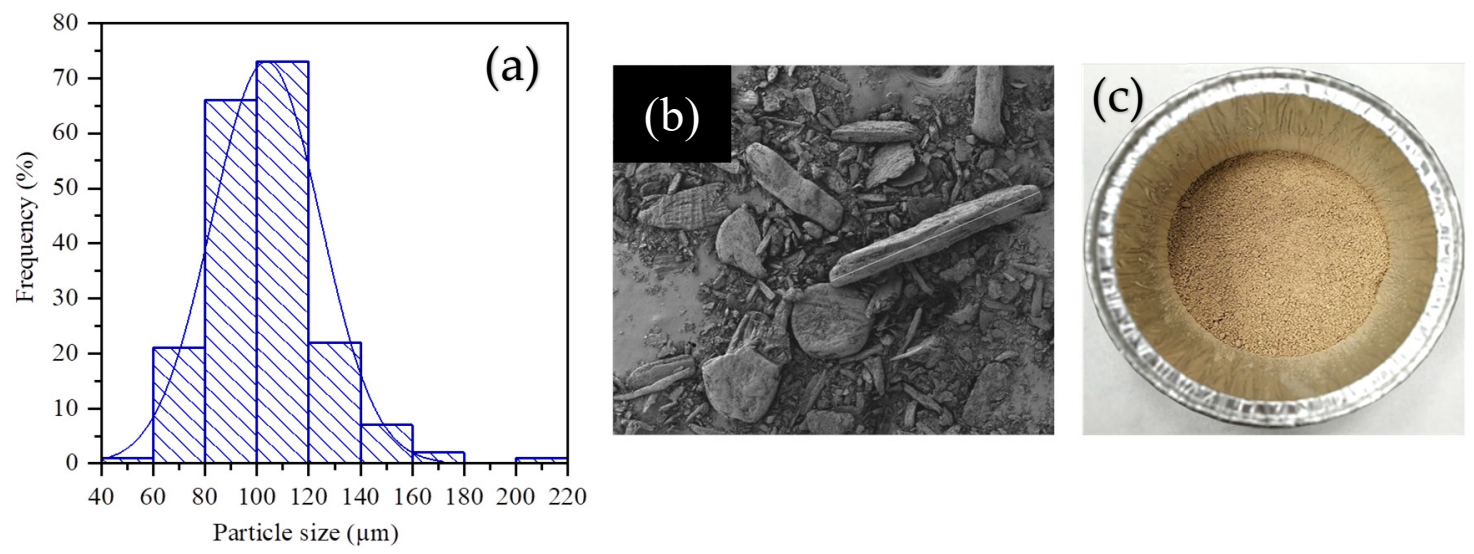

Figure 1. Detail of the coffee husk flour (CHF): (a) Particle size histogram; (b) Field emission scanning electron microscopy (FESEM) image taken at 55× with scale marker of $100 \mu \mathrm{m}$; (c) Visual aspect.

\subsection{Torrefaction of $\mathrm{CHF}$}

The resultant CHF was torrefied in a laboratory oven Carbolite mod. 2416CG from Keison Products (Barcelona, Spain). The flour was first dried at $105^{\circ} \mathrm{C}$ for $30 \mathrm{~min}$, then heated up under nitrogen atmosphere to the torrefaction temperature of $250^{\circ} \mathrm{C}$ at a heating rate of $5{ }^{\circ} \mathrm{C} / \mathrm{min}$, and finally this temperature was kept constant for $1 \mathrm{~h}$. The resulting torrefied husk was milled and sieved to the size of approximately $90 \mu \mathrm{m}$ using the same procedure applied in CHF to obtain the so-called TCHF (see Figure 2). 

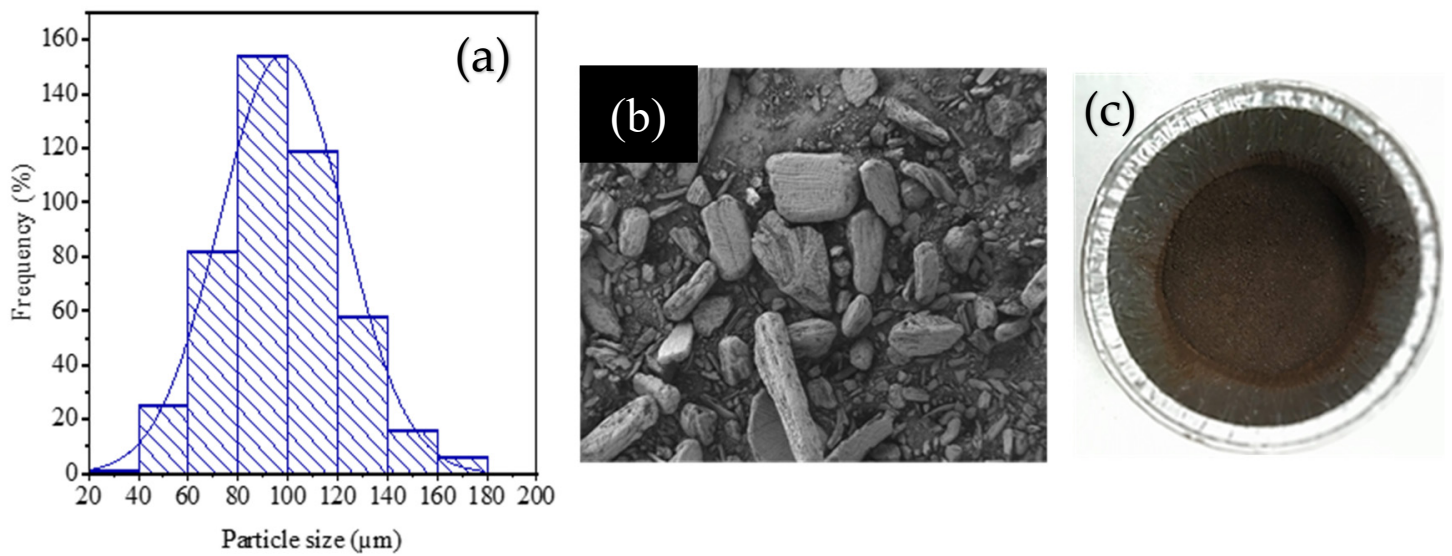

Figure 2. Detail of the torrefied coffee husk flour (TCHF): (a) Particle size histogram; (b) Field emission scanning electron microscopy (FESEM) image taken at 55× with scale marker of $100 \mu \mathrm{m}$; (c) Visual aspect.

\subsection{Preparation of the Green Composite Pieces}

The biopolymer pellets and the fillers were dried separately for $24 \mathrm{~h}$ at $60^{\circ} \mathrm{C}$ prior to processing. PLA and TCHF were mixed in a zipped bag according to the contents indicated in Table 1. These composition ranges were selected as previous studies with lignocellulosic materials in PLA indicated that excessive loss of properties occurs with higher amounts of lignocellulosic fillers [13,48,49]. The mixtures were melt-compounded in a co-rotating twin-screw extruder $(\mathrm{D}=25 \mathrm{~mm}, \mathrm{~L} / \mathrm{D}=24)$ from Dupra SL (Alicante, Spain), an equipment described in previous work [17]. The profile temperature was set, from the hopper to the die, to $165-170-175-180{ }^{\circ} \mathrm{C}$ and the rotating speed was $40 \mathrm{rpm}$. The extruded filaments were pelletized using an air-knife unit after being cooled down in an air stream. A green composite of PLA with $20 \mathrm{wt} \%$ of CHF was also prepared under the same conditions for comparison purposes.

Table 1. Set of samples prepared according to the weight percentage (wt\%) of polylactide (PLA), coffee husk flour (CHF), and torrefied coffee husk flour (TCHF).

\begin{tabular}{cccc}
\hline Sample & PLA (wt\%) & CHF (wt\%) & TCHF (wt\%) \\
\hline PLA & 100 & - & - \\
PLA/20CHF & 80 & 20 & - \\
PLA/20TCHF & 80 & - & 20 \\
PLA/30TCHF & 70 & - & 30 \\
PLA/40TCHF & 60 & - & 40 \\
PLA/50TCHF & 50 & - & 50 \\
\hline
\end{tabular}

The compounded pellets were thereafter injection molded to obtain pieces in a Meteor 270/75 from Mateu \& Solé (Barcelona, Spain). The profile of temperatures in the barrel was set, from the hopper to the injection nozzle, to $165-170-175-180^{\circ} \mathrm{C}$ and the mold temperature at $60^{\circ} \mathrm{C}$. A low injection time of $1 \mathrm{~s}$ was employed, whereas the applied clamping force was 20 tons and the pieces were cooled for $20 \mathrm{~s}$ in the mold. As a result, 4-mm pieces were produced that, prior to characterization, were stored for at least $48 \mathrm{~h}$.

\subsection{Mechanical Tests}

Tensile, flexural, hardness, and impact standard tests were carried out for mechanical characterization of the green composites. Pieces with a geometry of $80 \mathrm{~mm} \times 10 \mathrm{~mm} \times 4 \mathrm{~mm}$ were tested in a universal test machine ELIB 30 from S.A.E Ibertest (Madrid, Spain) equipped with a $5-\mathrm{kN}$ load cell in both tensile and flexural conditions. The guidelines of the International Organization for Standardization (ISO) 527 and ISO 178, were followed for the tensile and flexural tests using 
cross-head speeds of 10 and $5 \mathrm{~mm} / \mathrm{min}$, respectively. A Shore D durometer 673-D from Instrumentos J. Bot S.A. (Barcelona, Spain) was used to determine Shore D hardness according to ISO 868. The impact absorbed energy was determined following the ISO 179 in a Charpy pendulum of $6 \mathrm{~J}$ from Metrotec S.A. (San Sebastián, Spain) using unnotched samples of $80 \mathrm{~mm} \times 10 \mathrm{~mm} \times 4 \mathrm{~mm}$. For each mechanical test, at least six different samples were tested and the values were averaged.

\subsection{Microscopy}

The fracture surfaces of the pieces obtained from the impact tests were coated in a vacuum with an ultrathin aurum-palladium layer in a high vacuum sputter Emitech mod. SC7620 (Quorum Technologies Ltd., East Sussex, UK). Then, field emission scanning electron microscopy (FESEM) was performed to analyze their morphologies in high-resolution Zeiss Ultra55 (Oxford Instruments, Abingdon, UK) operating at $2 \mathrm{kV}$.

\subsection{Thermal Tests}

Sample pieces with a mass of $6.5 \pm 0.5 \mathrm{mg}$ were placed in crucibles and analyzed by differential scanning calorimetry (DSC) in a DSC calorimeter from Mettler-Toledo Inc. (Schwerzenbach, Switzerland) under a nitrogen atmosphere $(66 \mathrm{~mL} / \mathrm{min})$. The program consisted of a heating ramp from 30 to $250{ }^{\circ} \mathrm{C}$ to remove the thermal history, a cooling ramp down to $30^{\circ} \mathrm{C}$, and a second heating ramp to $350{ }^{\circ} \mathrm{C}$. A heating rate of $10^{\circ} \mathrm{C} / \mathrm{min}$ were used in all cases. The maximum degree of crystallinity $\left(X_{C_{-} \max }\right)$ was determined following Equation (1) [50]:

$$
X_{C_{-} \max }=\left[\frac{\Delta H_{m}}{\Delta H_{m}^{0} \cdot(1-w)}\right] \cdot 100(\%)
$$

where the melting enthalpy of PLA is $\Delta H_{m}(\mathrm{~J} / \mathrm{g})$, while the theoretical value of fully crystalline PLA is $\Delta H_{m}{ }^{\circ}(\mathrm{J} / \mathrm{g})$, taken as $93.7 \mathrm{~J} / \mathrm{g}$ [51], and the weight fraction of PLA in the sample is $1-w$.

Sample pieces with a mass of $15.5 \pm 0.5 \mathrm{mg}$ were placed in crucibles and subjected to thermogravimetric analysis (TGA) in a TGA/SDTA 851 thermobalance from Mettler-Toledo Inc. (Schwerzenbach, Switzerland). The samples were heated from 30 to $700{ }^{\circ} \mathrm{C}$ with a heating rate of $10^{\circ} \mathrm{C} / \mathrm{min}$ in nitrogen $(66 \mathrm{~mL} / \mathrm{min})$. All the thermal tests were performed in triplicate.

\subsection{Thermomechanical Tests}

The Vicat softening point (VST) and heat deflection temperature (HDT) of the green composite pieces were determined using a VICAT/HDT station mod. VHDT 20 (Metrotec S.A., San Sebastián, Spain). VST tests were carried out following the ISO 306 with a load of $5 \mathrm{~kg}$ and a heating rate of $50^{\circ} \mathrm{C} / \mathrm{h}$, whereas HDT measurements were performed according to the ISO 75 with a load of $320 \mathrm{~g}$ and a heating rate of $120^{\circ} \mathrm{C} / \mathrm{h}$.

Rectangular samples of $40 \mathrm{~mm} \times 10 \mathrm{~mm} \times 4 \mathrm{~mm}$ were subjected to dynamic mechanical thermal analysis (DMTA) in torsion mode using an AR-G2 oscillatory rheometer from TA Instruments (New Castle, DE, USA) equipped with a special clamp system for solid samples. The temperature program consisted of a thermal ramp from 30 to $140{ }^{\circ} \mathrm{C}$ at a heating rate of $2{ }^{\circ} \mathrm{C} / \mathrm{min}$. The maximum deformation percentage $(\gamma)$ was set to $0.1 \%$ at a frequency of $1 \mathrm{~Hz}$. All the thermomechanical tests were performed in triplicate.

\section{Results}

\subsection{Mechanical Performance of the Green Composite Pieces}

Table 2 includes the mechanical properties of PLA and its green composite pieces to ascertain the effect of the TCHF content on PLA. One can notice that neat PLA resulted in a brittle piece with an elongation at break $\left(\varepsilon_{b}\right)$ of nearly $9 \%$. The tensile strength at yield $\left(\sigma_{y}\right)$ was approximately $50 \mathrm{MPa}$ and 
the tensile modulus $\left(E_{t}\right)$ was $3.58 \mathrm{GPa}$. One can observe that the incorporation of both CHF and TCHF induced a progressive reduction in all the $\sigma_{y}$ and $\varepsilon_{b}$ values and an increase in $E_{t}$. For instance, with the addition of $20 \mathrm{wt} \%$ of $\mathrm{CHF}$, the $\sigma_{y}$ values diminished to $39.16 \mathrm{MPa}$ and with the addition of $20 \mathrm{wt} \%$ of $\mathrm{TCHF}$, the $\sigma_{y}$ values diminished to $43.29 \mathrm{MPa}$, which represent a percentage decrease of $21 \%$ and $13 \%$, respectively. Further reductions in the mechanical strength were observed at higher TCHF contents. For instance, the addition of $50 \mathrm{wt} \%$ of TCHF induced a percentage decrease of $\sim 44 \%$. Alternatively, the incorporation of CHF and TCHF improved the mechanical elasticity of the pieces. Thus, $E_{t}$ increased to 3.48 GPa for the PLA/CHF composite and it was in the 3.59-4.45 GPa range for the PLA/TCHF composite pieces. This result suggests than an efficient dispersion and wettability of the torrefied filler in the biopolymer matrix was achieved. With regard to ductility, the addition of the lignocellulosic fillers led to a percentage decrease from $8.91 \%$, for the neat PLA piece, to $6.98 \%$ for the PLA $/ 20 \mathrm{CH}$ piece, $7.10 \%$ for the PLA/20TCH piece, and finally to the lowest value of $5.18 \%$ for the PLA/50TCH piece. It can be thus considered that the coffee waste derived fillers acted as a stress concentrator rather than a reinforcing element in the biopolymer matrix. Furthermore, this result highlights the lack of miscibility between both composite components and also the low particle-polymer interfacial interactions. This effect was, however, more noticeable in the piece containing the untreated CHF and, most notably, for the pieces filled with the highest TCHF contents. The latter observation may suggest that TCHF poorly disperses in the PLA matrix at high content $[52,53]$. Therefore, as also demonstrated by Lessa et al. [54] for chitosan films containing waste coffee grounds (WCG), high amounts of TCHF cannot be efficiently distributed in the biopolymer matrix.

Table 2. Mechanical properties of the injection-molded pieces of polylactide (PLA) with coffee husk flour (CHF) and torrefied coffee husk flour (TCHF) in terms of tensile modulus $\left(E_{t}\right)$, tensile stress at yield $\left(\sigma_{y}\right)$, elongation at break $\left(\varepsilon_{b}\right)$, maximum flexural stress $\left(\sigma_{f}\right)$, flexural modulus $\left(E_{f}\right)$, Shore D hardness, and impact strength.

\begin{tabular}{cccccccc}
\hline Piece & $E_{t}(\mathbf{G P a})$ & $\sigma_{\boldsymbol{y}} \mathbf{( M P a )}$ & $\varepsilon_{\boldsymbol{b}} \mathbf{( \% )}$ & $\boldsymbol{E}_{\boldsymbol{f}} \mathbf{( G P a )}$ & $\sigma_{f} \mathbf{( M P a )}$ & $\begin{array}{c}\text { Shore D } \\
\text { Hardness }\end{array}$ & $\begin{array}{c}\text { Impact Strength } \\
\left.\mathbf{( k J} / \mathbf{m}^{2}\right)\end{array}$ \\
\hline PLA & $3.58 \pm 0.37$ & $49.51 \pm 1.92$ & $8.91 \pm 0.71$ & $3.17 \pm 0.19$ & $98.88 \pm 1.18$ & $78.65 \pm 2.64$ & $25.10 \pm 2.01$ \\
PLA/20CHF & $3.48 \pm 0.78$ & $39.16 \pm 0.69$ & $6.98 \pm 1.10$ & $4.02 \pm 0.20$ & $84.88 \pm 1.35$ & $81.04 \pm 1.38$ & $12.00 \pm 0.39$ \\
PLA/20TCHF & $3.59 \pm 0.53$ & $43.29 \pm 1.90$ & $7.10 \pm 0.47$ & $4.33 \pm 0.19$ & $90.96 \pm 2.18$ & $81.10 \pm 2.02$ & $12.44 \pm 2.17$ \\
PLA/30TCHF & $3.66 \pm 0.87$ & $36.23 \pm 1.83$ & $5.92 \pm 0.36$ & $4.48 \pm 0.27$ & $73.58 \pm 1.71$ & $82.05 \pm 1.80$ & $8.85 \pm 1.67$ \\
PLA/40TCHF & $4.22 \pm 1.07$ & $30.33 \pm 2.16$ & $5.59 \pm 0.45$ & $5.10 \pm 0.34$ & $71.66 \pm 2.21$ & $82.10 \pm 2.16$ & $7.19 \pm 0.31$ \\
PLA/50TCHF & $4.45 \pm 1.04$ & $27.81 \pm 1.65$ & $5.18 \pm 0.91$ & $5.53 \pm 0.40$ & $61.42 \pm 2.04$ & $85.05 \pm 1.19$ & $7.19 \pm 0.97$ \\
\hline
\end{tabular}

Nevertheless, one should also consider that this mechanical reduction was relatively low in terms of the high amount of lignocellulosic filler when compared with those attained in previously prepared green composites of PLA and coffee waste derived fillers. For instance, in the work reported by Suaduang et al. [55], the tensile strength at break $\left(\sigma_{b}\right)$ of PLA films decreased from $79.20 \mathrm{MPa}$ (transverse direction, TD) and $72.79 \mathrm{MPa}$ (machine direction, MD) to 20.77 MPa (TD) and $18.31 \mathrm{MPa}$ (MD) after the incorporation of $10 \mathrm{wt} \%$ of SCG. In another study, the $\sigma_{b}$ value of PLA films decreased from $44.3 \mathrm{MPa}$ to approximately $20 \mathrm{MPa}$ after the incorporation of $40 \mathrm{wt} \%$ of SCG, which was attributed to the poor filler dispersion in the biopolymer matrix due to its low compatibility [56]. The improvement attained here may be attributed to the removal of impurities and other volatile TCHF components during torrefaction that would otherwise decrease the strength of interfacial interactions and adhesion between the filler and PLA matrix. Furthermore, the resultant increase in hydrophobicity of the lignocellulosic filler after torrefaction can also be a meaningful explanation for the improved mechanical properties attained in the green composite pieces with TCHF in comparison with the pieces based on untreated CHF. In this regard, one can expect that the higher presence of moisture in CHF can promote a larger decrease in the PLA's $M_{W}$ during processing at high temperature due to hydrolysis of the ester groups, which can result in impairment of the final mechanical properties [57].

The flexural modulus $\left(E_{f}\right)$ and strength $\left(\sigma_{f}\right)$ of the unfilled PLA piece were $3.17 \mathrm{GPa}$ and nearly $99 \mathrm{MPa}$, respectively. Similar to the tensile properties, the incorporation of TCHF yielded a progressive 
increase in $E_{f}$ and a reduction in $\sigma_{f}$. In particular, the green composite pieces filled with $50 \mathrm{wt} \%$ of TCHF showed a $E_{f}$ value of $5.53 \mathrm{GPa}$, which is approximately 1.7 times higher than that of the unfilled PLA, whereas $\sigma_{f}$ was reduced to $61.42 \mathrm{MPa}$. Some previous studies have reported similar mechanical properties of green composites based on coffee waste derived fillers. For instance, Dominici et al. [58] showed a worsening of tensile strength and ductility when CSS was incorporated into bio-based high-density polyethylene (bio-HDPE). The described decrease of the mechanical properties was ascribed to the low aspect ratio of the CSS particles as well as their poor adhesion to the biopolymer matrix. In this regard, the use of coupling agents has improved both the tensile strength and ductility of PLA composites prepared with SCG, though the improvements achieved were relatively low and their overall and specific migration limits (OML and SML) should also be carefully determined [59].

One can also observe that, as the TCHF content increased, hardness also increased. The Shore $\mathrm{D}$ hardness value increased from 78.65, for the unfilled PLA piece, to 85.05 for the PLA/50TCH piece. This change in the mechanical behavior corresponds to the typical effect of a relatively stiff lignocellulosic filler on a polymer matrix [60]. In contrast to hardness, the impact absorbed energy of PLA progressively decreased after the TCHF incorporation. The impact energy of the neat PLA piece was $25.10 \mathrm{~kJ} / \mathrm{m}^{2}$ and it was reduced down to $7.19 \mathrm{~kJ} / \mathrm{m}^{2}$ for the green composite piece filled with $50 \mathrm{wt} \%$ of TCHF. This notable decrease in toughness can be related to the poor matrix-particle interactions, which could promote microcrack formations and stress concentrations during the impact test [60]. Therefore, the addition of the coffee waste derived lignocellulosic filler led to a more elastic and stiffer material, but the matrix-filler continuity was not achieved, and an early fracture was attained. Thus, in terms of mechanical performance, PLA pieces containing $20 \mathrm{wt} \%$ of TCHF were slightly more resistant but less ductile, showing characteristics comparable to those of neat PLA.

\subsection{Aspect and Morphology of the Green Composite Pieces}

Figure 3 shows the visual aspect of the injection-molded pieces of PLA, PLA filled with $20 \mathrm{wt} \%$ of $\mathrm{CHF}$ and TCHF, that is, PLA/20CHF and PLA/20TCHF, respectively. The increase in the characteristic dark brown color produced in the pieces of the green composites is due to the Maillard reaction of coffee husk, which took place during the torrefaction and its subsequent melt processing with PLA, leading to formation of melanoidins [35].

(a)

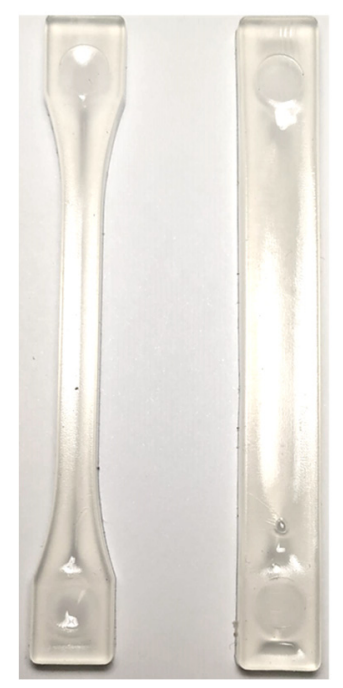

(b)

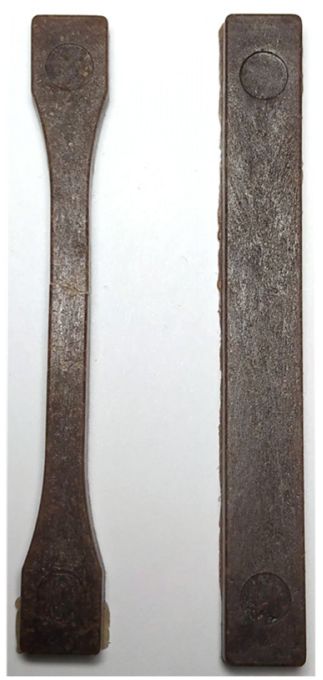

(c)

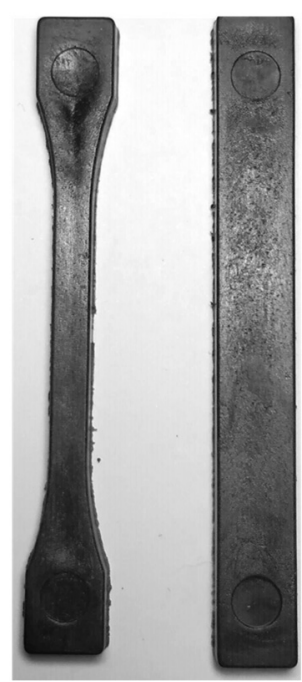

Figure 3. Visual aspect of the injection-molded pieces of: (a) Neat polylactide (PLA); (b) PLA filled with $20 \mathrm{wt} \%$ of coffee husk flour (CHF); (c) PLA filled with $20 \mathrm{wt} \%$ of torrefied coffee husk flour (TCHF). 
The fracture surfaces after the impact tests of the neat PLA piece and the PLA/CHF and PLA/TCHF pieces at different filler contents are shown in Figure 4. The unfilled PLA piece, shown in Figure 4a, presented a typical brittle fracture with low plastic deformation [61]. In Figure $4 b$, one can see that the incorporation of untreated CHF led to a similar fracture surface but yet softer, indicating that the toughness of the piece was reduced. One can also observe the formation of a large gap between the coffee waste derived lignocellulosic fillers and the biopolymer PLA matrix, which points to their weak interactions [62,63]. The morphology of the green composite based on $20 \mathrm{wt} \% \mathrm{of}$ TCHF, shown in Figure 4c, changed to a rougher surface, also showing a reduction in the filler-to-matrix gaps. However, no enhanced yielding was detected, which is in agreement with the ductility decrease reported in Table 2. In the case of the green composites prepared at higher TCHF contents, shown in Figure $4 \mathrm{~d}-\mathrm{f}$, one can see that the fracture surface roughness increased with the filler addition. Moreover, the FESEM micrographs displayed some large voids, microcracks, and gaps in the interface between both components, that is, PLA and TCHF. This phenomenon led to a stiffer material, but with reduced impact absorbed energy, as also shown during the mechanical analysis. One can also observe in the FESEM micrographs that the PLA/TCHF pieces prepared at the highest filler contents, that is, $40 \mathrm{wt} \%$ and $50 \mathrm{wt} \%$, showed the co-presence of single particles and irregular aggregates, being distributed randomly within the PLA matrix. Similar observations were described for pectin/coffee ground composites in which the formation of aggregates was ascribed to the prevalence of particle-particle interactions over the forces between the composite components [64].
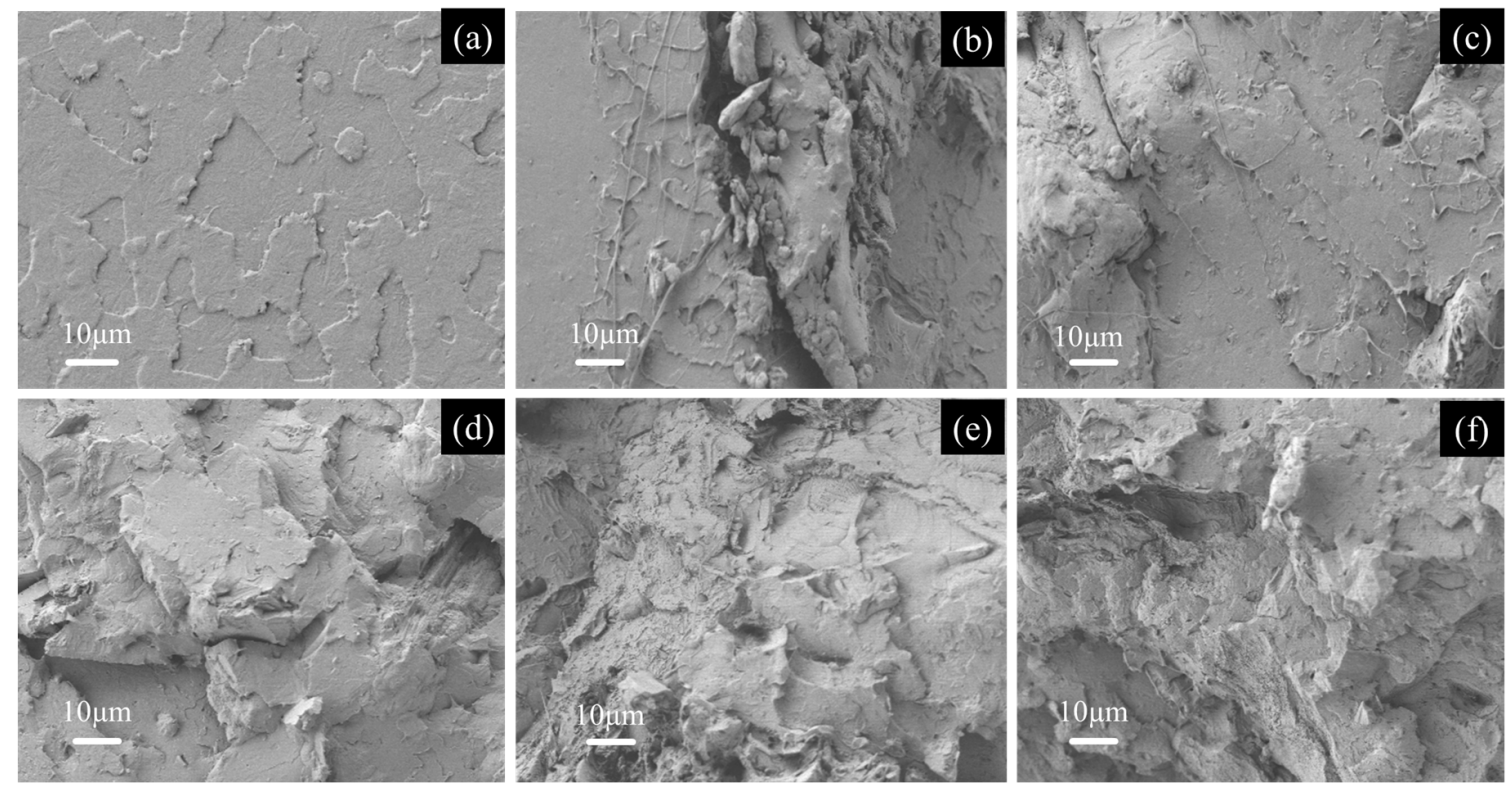

Figure 4. Field emission scanning electron microscopy (FESEM) images of the fracture surfaces of the injection-molded pieces of polylactide (PLA) with coffee husk flour (CHF) and torrefied coffee husk flour (TCHF): (a) Neat PLA; (b) PLA/20CHF; (c) PLA/20TCHF; (d) PLA/30TCH; (e) PLA/40TCH; (f) PLA/50TCH. Images were taken at $500 \times$ with scale markers of $10 \mu \mathrm{m}$.

\subsection{Thermal Performance of the Green Composite Pieces}

Figure 5 shows the DSC thermograms of PLA and its green composites with CHF and TCHF. Table 3 gathers the main thermal properties obtained from the cooling and the second heating scans, once the thermal history was removed from the samples. The neat PLA sample showed a glass transition temperature $\left(T_{g}\right)$ of $62.3^{\circ} \mathrm{C}$ and the incorporation of TCHF led to a slight decrease in the values up to $60.7^{\circ} \mathrm{C}$ for the green composite filled at $50 \mathrm{wt} \%$. In all curves, a low-intense endothermic peak was observed, which can be ascribed to the aging process of the biopolyester [42]. It can also be observed in Figure 5a that, during cooling, the PLA samples did not crystallize from the melt. 
In contrast, in Figure $5 b$, one can see that the neat PLA samples showed an exothermic peak centered at $122.7^{\circ} \mathrm{C}$ for neat PLA, which is ascribed to the biopolyester chain rearrangement during cold crystallization. The green composites showed slightly higher values of both cold crystallization temperature $\left(T_{c c}\right)$ and cold crystallization enthalpy $\left(\Delta H_{c c}\right)$, showing the highest values for TCHF contents of $20 \mathrm{wt} \%$ and $30 \mathrm{wt} \%$, respectively. The cold crystallization process is an exothermic process that takes place when the biopolymer chains become flexible, above PLA's $T_{g}$, which is caused by a primary nucleation, by which an ordered state is achieved. Since more PLA mass could cold crystallize, one can consider that intermediate filler amounts favored crystallization of PLA. A second endothermic peak, corresponding to the melting temperature $\left(T_{m}\right)$, was observed at $151.3^{\circ} \mathrm{C}$ for neat PLA, which slightly increased for filler contents of $20 \mathrm{wt} \%$ and then decreased for higher contents. An anticipation of the melting phenomena was also observed in HDPE by Arrigo et al. [65] after the addition of biochar particles derived from waste coffee grounds. This behavior was explained by the presence of specific interactions occurring between the biopolymer chains and the particle interfaces. In fact, the lower $T_{m}$ values attained at the highest contents, that is, $40 \mathrm{wt} \%$ and $50 \mathrm{wt} \%$ of TCHF, in combination with the higher $\Delta H_{c c}$ values, suggest that the biopolymer chains were immobilized onto the surface of the lignocellulosic fillers. The maximum degree of crystallinity, that is, $X_{C_{-} \max }$, which does not consider the crystals that are formed during cold crystallization [50], increased progressively up to a TCHF content of $30 \mathrm{wt} \%$ and then slightly lower values were observed. This result indicates that the lignocellulosic fillers induced a nucleating effect that favored the formation of crystals in the green composites. In the case of the lower $X_{C_{-} \max }$ values for the green composites containing $40 \mathrm{wt} \%$ and $50 \mathrm{wt} \%$ of TCHF, one can consider that the fillers presence at these contents also supposed an obstacle for the biopolymer chains to form stable crystals, generating a negative effect on crystallinity and leading to the formation of a more amorphous structure [66-68]. Furthermore, one can also observe that the torrefaction process did not yield any significant effect on the thermal properties of PLA at the studied filler loading, suggesting that nucleation was based on a physical phenomenon.

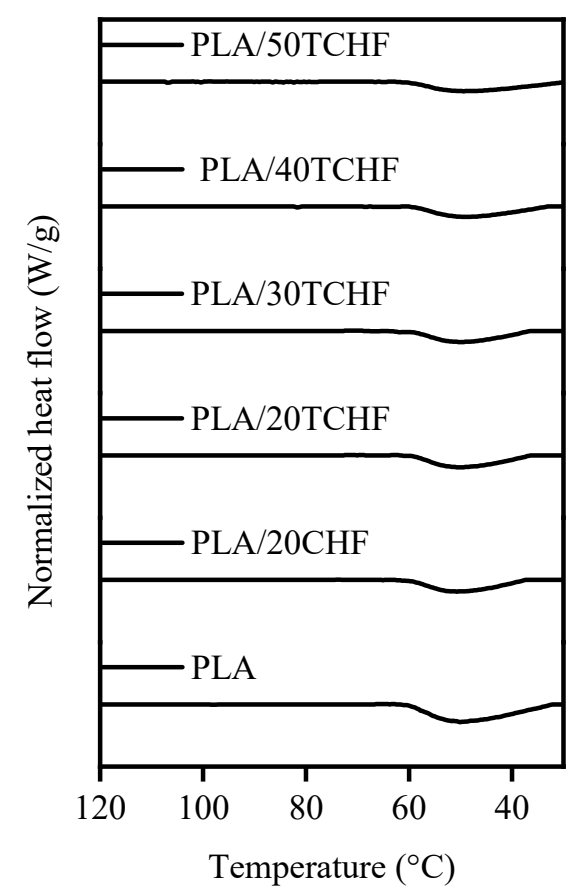

(a)

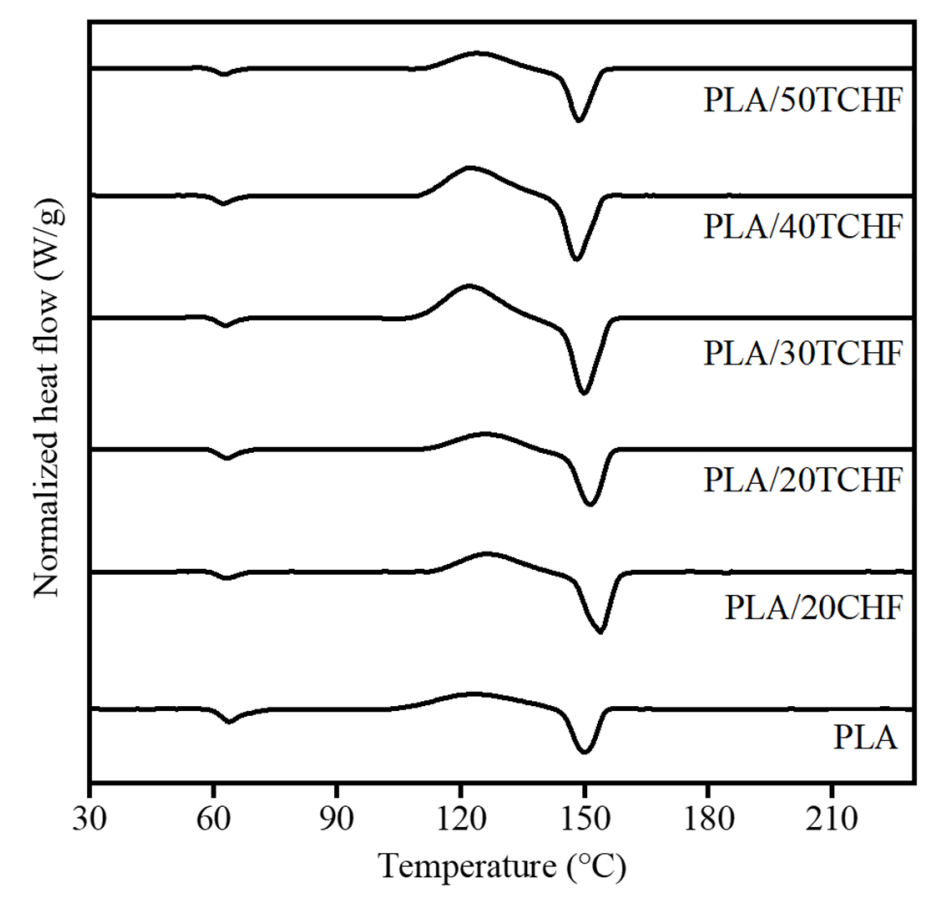

(b)

Figure 5. Differential scanning calorimetry (DSC) thermograms taken during (a) cooling and (b) second heating of the injection-molded pieces of polylactide (PLA) with coffee husk flour (CHF) and torrefied coffee husk flour (TCHF). 
Table 3. Thermal properties of the injection-molded pieces of polylactide (PLA) with coffee husk flour (CHF) and torrefied coffee husk flour (TCHF) in terms of glass transition temperature $\left(T_{g}\right)$, cold crystallization temperature $\left(T_{c c}\right)$, melting temperature $\left(T_{m}\right)$, cold crystallization enthalpy $\left(\Delta H_{c c}\right)$, melting enthalpy $\left(\Delta H_{m}\right)$, and maximum degree of crystallinity $\left(X_{C_{-} \text {max }}\right)$.

\begin{tabular}{ccccccc}
\hline Piece & $\boldsymbol{T}_{\boldsymbol{g}}\left({ }^{\circ} \mathbf{C}\right)$ & $\boldsymbol{T}_{\boldsymbol{c c}}\left({ }^{\circ} \mathbf{C}\right)$ & $\Delta \boldsymbol{H}_{c c}(\mathrm{~J} / \mathbf{g})$ & $\boldsymbol{T}_{\boldsymbol{m}}\left({ }^{\circ} \mathrm{C}\right)$ & $\Delta \boldsymbol{H}_{m}(\mathrm{~J} / \mathbf{g})$ & $\boldsymbol{X}_{\boldsymbol{C}_{-} \max }(\mathbf{\%})$ \\
\hline PLA & $62.3 \pm 0.4$ & $122.7 \pm 1.9$ & $4.30 \pm 0.35$ & $151.3 \pm 0.4$ & $11.32 \pm 0.99$ & $12.08 \pm 1.80$ \\
PLA/20CHF & $61.3 \pm 0.3$ & $124.7 \pm 1.3$ & $8.04 \pm 0.42$ & $153.7 \pm 0.5$ & $15.17 \pm 1.10$ & $20.24 \pm 1.60$ \\
PLA/20TCHF & $61.8 \pm 0.4$ & $125.9 \pm 1.0$ & $7.10 \pm 0.55$ & $152.6 \pm 0.3$ & $15.92 \pm 0.75$ & $21.24 \pm 2.02$ \\
PLA/30TCHF & $61.3 \pm 0.4$ & $122.1 \pm 0.3$ & $17.80 \pm 0.76$ & $150.7 \pm 0.6$ & $19.59 \pm 0.14$ & $29.87 \pm 2.35$ \\
PLA/40TCHF & $61.3 \pm 0.8$ & $121.8 \pm 0.6$ & $12.27 \pm 0.94$ & $149.9 \pm 0.5$ & $14.35 \pm 0.59$ & $25.52 \pm 1.49$ \\
PLA/50TCHF & $60.7 \pm 0.5$ & $123.2 \pm 0.9$ & $10.27 \pm 0.35$ & $149.6 \pm 0.4$ & $12.05 \pm 0.99$ & $25.72 \pm 0.80$ \\
\hline
\end{tabular}

The TGA and first derivate thermogravimetric (DTG) curves of the injection-molded pieces of PLA and its green composite pieces with CHF and TCHF are shown in Figure 6, whereas Table 4 shows the relevant values extracted from the curves. In relation to the thermal degradation profiles of CHF and TCHF, in both cases they presented three stages; however, the torrefied fillers showed significantly higher stability. The first mass loss, which occurred below $100{ }^{\circ} \mathrm{C}$, being in both cases less than $5 \%$ but slightly higher for $\mathrm{CHF}$, is associated with the evaporation of moisture and volatiles present in the lignocellulosic fillers. The second one occurred between approximately 240 and $380{ }^{\circ} \mathrm{C}$, was the most intense, and was associated with a mass loss of over $60 \%$ and $35 \%$ for $\mathrm{CHF}$ and TCHF, respectively. This degradation stage, which was also more intense for $\mathrm{CHF}$, is mainly caused by the thermal decomposition of the molecular bonds of hemicellulose, cellulose, and small amounts of lignin, which overlapped with the thermal degradation of PLA. The third stage started at $385^{\circ} \mathrm{C}$ and continued for the whole thermal range tested. This last mass loss is due to the degradation of the lignin fraction present in CHF and TCHF [11,69]. In this regard, de Brito et al. [70] showed that green coffee cake (GCC), a solid by-product of the coffee processing industry, resulting from the extraction of oil by the cold pressing technique, also presented three regions of mass loss, similar to other lignocellulosic biomasses. The first one was observed between 50 and $100{ }^{\circ} \mathrm{C}$, the second one between 200 and $300{ }^{\circ} \mathrm{C}$, and the last one between 275 and $400{ }^{\circ} \mathrm{C}$. The authors ascribed the second and third mass losses to hemicellulose depolymerization in combination with temperature-induced glycosidic cleavage and to lignin components and cellulose degradation, respectively. Finally, after the degradation steps, a significant residue of approximately $25 \%$ and $40 \%$ was found for CHF and TCHF, respectively, remarking the higher stability of the carbon formed during the torrefaction step. The TGA results also indicated that TCHF was thermally stable up to more than $250{ }^{\circ} \mathrm{C}$, which makes it useful as a reinforcing agent in most WPCs.

In the case of PLA, it can be observed that the biopolymer degraded in a quick step process at approximately $350^{\circ} \mathrm{C}$. The main products generated during the thermal degradation of PLA have been ascribed to lactic acid, oligomers of lactic acid (OLAs), acetaldehydes, carbon dioxide, carbon monoxide, and ketones [60]. The TGA curves of the PLA/TCHF pieces showed a slight increase in the thermal stability for the lowest filler content. In particular, the DTG curves showed an increase in the pyrolysis peak related to the degradation temperature $\left(T_{d e g}\right)$ from $347.4^{\circ} \mathrm{C}$, for neat PLA, up to $354.7^{\circ} \mathrm{C}$, for the PLA/20TCHF composite. The increase in the thermal stability of the green composite pieces can be related to the "barrier" effect of the decomposition of the biopolymer material by the lignocellulosic fillers, which promoted an increase of the degradation temperature [70]. However, a decrease in the temperature at the mass loss of $5 \%\left(\mathrm{~T}_{5 \%}\right)$, which corresponds to the onset degradation temperature, was observed for TCHF contents above $30 \mathrm{wt} \%$. The lower $\mathrm{T}_{5} \%$ values attained at higher filler contents can be related to the "chimney" effect of the coffee waste lignocellulosic fillers, which prevails their "barrier" effect, and favored the movement of heat in the PLA matrix [57]. In particular, $\mathrm{T}_{5 \%}$ was reduced from $320.4{ }^{\circ} \mathrm{C}$, for the unfilled PLA piece, down to approximately $300{ }^{\circ} \mathrm{C}$ for TCHF contents of $40 \mathrm{wt} \%$ and $50 \mathrm{wt} \%$. Therefore, a slight improvement in the PLA's thermal stability was attained 
with the addition of $20 \mathrm{wt} \%$ of TCHF, whereas a negative effect was observed for the pieces filled with higher TCHF contents. It is noteworthy that a higher thermal stability was observed in comparison to the PLA composites prepared with CSS by Totaro et al. [71], who ascribed the decrease to both the metals present and the moisture released by the fillers, which can catalyze degradation and induce hydrolysis of the ester groups, respectively. Since lower thermal stability values were attained for the PLA/20CHF piece, the improvement attained herein is an indication that the less thermally stable compounds, such as hemicellulose and cellulose, were successfully removed during the torrefaction step [33], leading to a material with higher lignocellulosic content and, hence, improved thermal stability. Furthermore, as expected, one can observe that adding TCHF caused the char residue to increase. Such high char content is also related to the torrefaction step, which can generate a higher percentage of carbon compared with the non torrefied lignocellulosic filler [33].

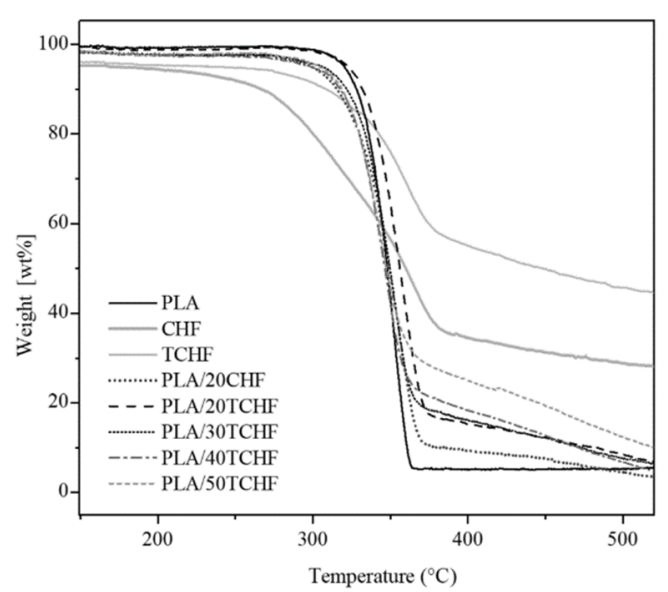

(a)

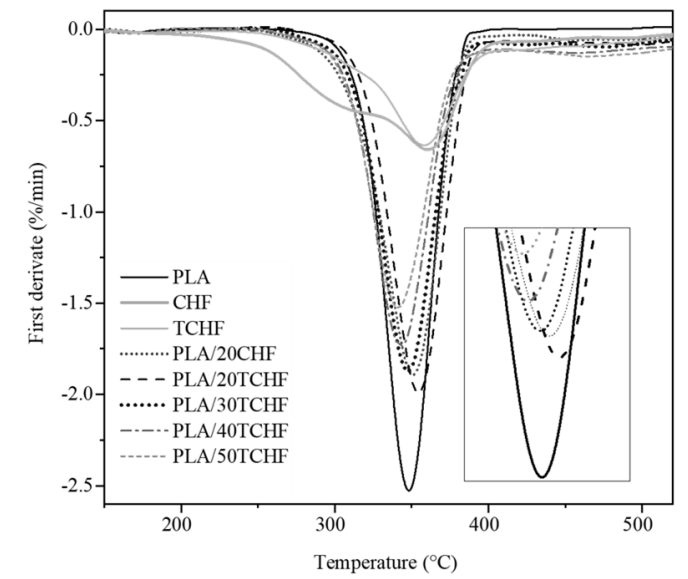

(b)

Figure 6. (a) Thermogravimetric analysis (TGA) and (b) first derivate thermogravimetric (DTG) curves of the injection-molded pieces of polylactide (PLA) with coffee husk flour (CHF) and torrefied coffee husk flour (TCHF).

Table 4. Main thermal degradation parameters of the injection-molded pieces of polylactide (PLA) with coffee husk flour (CHF) and torrefied coffee husk flour (TCHF) in terms of temperature at mass loss of $5 \%\left(\mathrm{~T}_{5 \%}\right)$, degradation temperature $\left(\mathrm{T}_{\mathrm{deg}}\right)$, and residual mass at $700{ }^{\circ} \mathrm{C}$.

\begin{tabular}{cccc}
\hline Piece & $\mathbf{T}_{\mathbf{5} \%}\left({ }^{\circ} \mathbf{C}\right)$ & $\mathbf{T}_{\mathbf{d e g}}\left({ }^{\circ} \mathbf{C}\right)$ & Residual Mass $(\%)$ \\
\hline CHF & $237.8 \pm 1.2$ & $360.6 \pm 2.2$ & $25.2 \pm 0.3$ \\
TCHF & $252.1 \pm 1.3$ & $357.8 \pm 1.3$ & $39.6 \pm 0.3$ \\
PLA & $320.4 \pm 2.3$ & $347.4 \pm 1.4$ & $5.6 \pm 0.3$ \\
PLA/20CHF & $298.9 \pm 1.6$ & $351.1 \pm 2.2$ & $3.2 \pm 0.6$ \\
PLA/20TCHF & $322.4 \pm 1.7$ & $354.7 \pm 2.2$ & $5.6 \pm 0.5$ \\
PLA/30TCHF & $306.0 \pm 1.3$ & $347.7 \pm 1.7$ & $8.1 \pm 0.4$ \\
PLA/40TCHF & $299.8 \pm 1.8$ & $343.5 \pm 1.8$ & $9.7 \pm 0.7$ \\
PLA/50TCHF & $301.1 \pm 1.3$ & $341.4 \pm 1.6$ & $10.9 \pm 0.8$ \\
\hline
\end{tabular}

\subsection{Thermomechanical Performance of the Green Composite Pieces}

Table 5 shows the VST and HDT values of the injection-molded pieces of neat PLA and PLA/TCHF, which are important thermomechanical parameters that can be used to estimate their upper useful temperature limit for uses in, for instance, packaging or disposables. VST, which reflects the material's softening by temperature rises, increased progressively from $56.6^{\circ} \mathrm{C}$, for neat PLA, to $59.9^{\circ} \mathrm{C}$, for PLA/50TCH, respectively, following an evolution similar to that found in hardness. This result is in agreement with the study of Huang et al. [52], who showed that the VST of HDPE increased with the loading of coffee husk fiber (CHF), which was attributed to a fiber 
reinforcement that prevented deformation of the composites. Concerning HDT, the values evolved in a similar manner to VST, showing a slight and progressive increase from $51{ }^{\circ} \mathrm{C}$, for neat PLA, to $54.1^{\circ} \mathrm{C}$ for PLA/50TCHF. This enhanced thermomechanical resistance can be attributed to the higher modulus and amount of crystallinity, since both parameters increased with increasing TCHF content. Similar results were obtained by Sarasini et al. [72], who showed that the softening point of $\mathrm{PBAT} /$ poly(3-hydroxybutyrate-co-3-hydroxyvalerate) (PHBV) blends increased up to $3{ }^{\circ} \mathrm{C}$ with the incorporation of CSS.

Table 5. Thermomechanical properties of the injection-molded pieces of polylactide (PLA) with torrefied coffee husk flour (TCHF) in terms of Vicat softening point (VST) and heat deflection temperature (HDT).

\begin{tabular}{ccc}
\hline Piece & VST $\left({ }^{\circ} \mathbf{C}\right)$ & HDT $\left({ }^{\circ} \mathbf{C}\right)$ \\
\hline PLA & $56.6 \pm 0.6$ & $51.0 \pm 0.8$ \\
PLA/20TCHF & $57.8 \pm 0.8$ & $52.3 \pm 0.8$ \\
PLA/30TCHF & $58.1 \pm 0.9$ & $52.8 \pm 0.9$ \\
PLA/40TCHF & $59.4 \pm 0.6$ & $53.2 \pm 0.7$ \\
PLA/50TCHF & $59.9 \pm 0.3$ & $54.1 \pm 0.8$ \\
\hline
\end{tabular}

Finally, Figure 7 shows the mechanical performance of the green composite pieces under dynamic load conditions as a function of temperature. Figure 7a displays the evolution of the storage modulus with temperature. In the temperature range between 30 and $50{ }^{\circ} \mathrm{C}$, below the glass transition region, the incorporation of TCHF produced an increase in the storage modulus of PLA. This behavior indicates that the addition of the TCHF filler led to a stiffer material since the lignocellulosic particles restricted the biopolymer chain mobility and also promoted crystallization as described above during the thermal characterization. From approximately $55^{\circ} \mathrm{C}$, a prominent decrease in the storage modulus due the glass transition process can be seen [41]. In addition, from nearly $90^{\circ} \mathrm{C}$, an increment in the storage modulus was detected. This phenomenon is associated with the cold crystallization of PLA. During this process, the biopolymer chains reorganize into a more compact structure, leading to an increase in the storage modulus [73]. Furthermore, as more TCHF powder was added, in agreement with the previous DSC analysis, a slight decrease in the cold crystallization temperature was noticed.

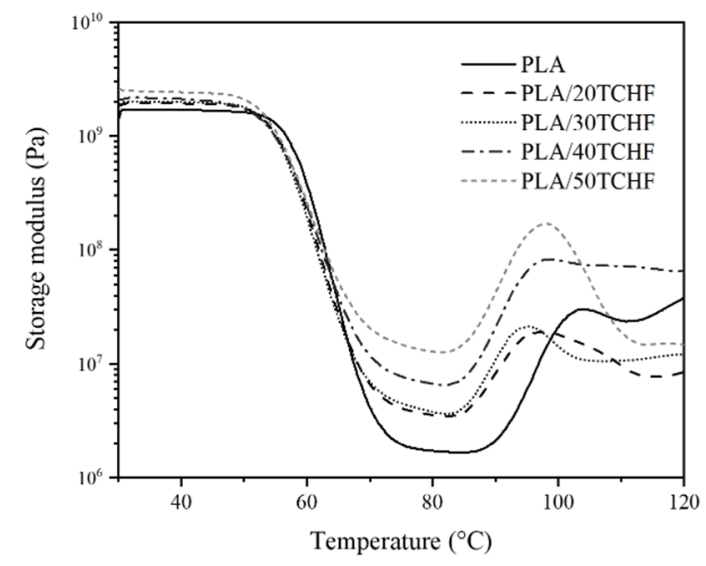

(a)

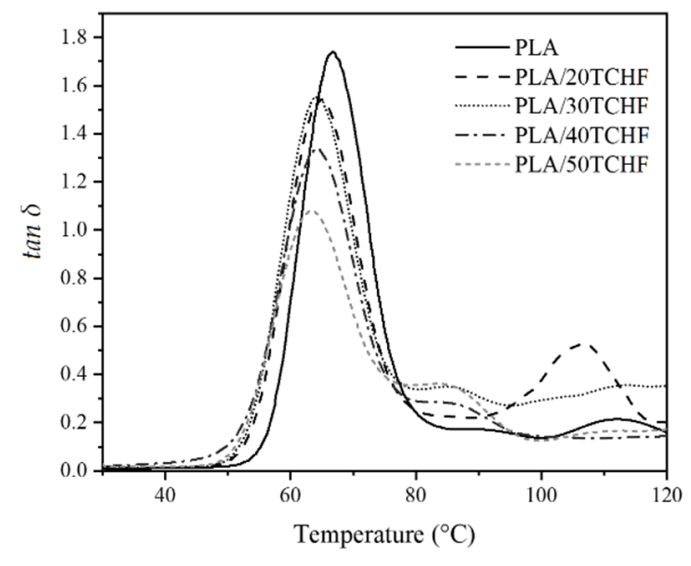

(b)

Figure 7. Evolution as a function of temperature of the (a) storage modulus and (b) dynamic damping factor $(\tan \delta)$ of the injection-molded pieces of polylactide (PLA) with torrefied coffee husk flour (TCHF).

Figure $7 \mathrm{~b}$ displays the evolution as a function of temperature of the damping factor $(\tan \delta)$ for the unfilled PLA piece and the PLA/TCHF composite pieces. The peak for the neat PLA progressively shifted to lower values as more filler was added. It particularly decreased from $68.7^{\circ} \mathrm{C}$, for the neat PLA piece, down to values in the $62-64^{\circ} \mathrm{C}$ range. This peak is ascribed to the alpha $(\alpha)$-transition of 
PLA, being in relation to the PLA's $T_{g}$. One can expect that with a greater interaction between filler and biopolymer matrix, which can be achieved by modifying the fiber surface during the torrefaction step, there would be a restriction on the movement of the macromolecular chains located on the surface of the fillers and, hence, an increase in $T_{g}$ [74]. However, the reduction attained in $T_{g}$, also observed by DSC, suggests that the fillers allowed an increase in the free volume in the green composites, thus indicating low compatibility or poor interaction with PLA [70]. This behavior confirms that the movement of the amorphous PLA was promoted by the coffee waste derived lignocellulosic fillers and it suggests that shorter biopolymer chains were formed due to a chain scission. Furthermore, the nucleating effect of TCHF was further corroborated by the gradual reduction in the $\tan \delta$ peak intensities of the green composite pieces. The latter indicates that the number of molecules experimenting glass transition was reduced by the fillers' presence [75].

\section{Conclusions}

The results achieved in this study demonstrate that coffee husk, a large food processing by-product, can be used in the form of flour as a reinforcing filler in green composites. Torrefaction, a mild form of pyrolysis at $250^{\circ} \mathrm{C}$ in reduced atmosphere, yielded more thermally stable biomass that was also more hydrophobic and, hence, more compatible with PLA. Characterization of the injection-molded PLA/TCHF pieces showed a positive effect on the overall mechanical improvement and a thermal stability enhancement with the addition of $20 \mathrm{wt} \%$ of TCHF. However, the green composites filled with $30 \mathrm{wt} \%, 40 \mathrm{wt} \%$, and $50 \mathrm{wt} \%$ showed lower performance, although they are still interesting due to the high amount of waste that can be valorized. Both elasticity and hardness increased, whereas ductility and toughness decreased, for all of the TCHF contents due to the lack of interaction as observed by FESEM. In contents of up to $30 \mathrm{wt} \%$, the lignocellulosic fillers induced a nucleating effect that favored the formation of PLA crystals and showed sufficient thermal stability. Furthermore, the addition of TCHF led to slightly higher VST and HDT values and the thermomechanical resistance of PLA was improved, meaning the resultant pieces were able to withstand temperatures of up to nearly $60^{\circ} \mathrm{C}$. In a Circular Bioeconomy context, the resultant PLA/TCHF composite pieces prepared with $20 \mathrm{wt} \%$ of the torrefied coffee waste derived filler can be used for rigid packaging, cups and containers, and food contact disposables, such as cutlery and plates, where novel compostable and sustainable materials with high stiffness and low thermal resistance are required.

Author Contributions: Conceptualization, O.F. and J.A.A.-P.; methodology, D.L.O.-B., Y.J.R.-O. and J.A.A.-P.; validation, O.F. and S.T.-G.; formal analysis, O.F.; investigation, D.L.O.-B., Y.J.R.-O. and J.A.A.-P.; data curation, D.L.O.-B. and Y.J.R.-O.; writing-original draft preparation, J.A.A.-P. and O.F.; writing-review and editing, S.T.-G.; visualization, O.F. and J.A.A.-P.; funding acquisition, O.F., J.A.A.-P. and S.T.-G. All authors have read and agreed to the published version of the manuscript.

Funding: This research work was funded by the Spanish Ministry of Science and Innovation (MICI), project numbers RTI2018-097249-B-C21 and MAT2017-84909-C2-2-R, and by the Industrial University of Santander.

Acknowledgments: S.T.-G. acknowledges MICI for his Juan de la Cierva-Incorporación contract (IJCI-2016-29675). Microscopy services at UPV are also acknowledged for their help in collecting the FESEM images.

Conflicts of Interest: The authors declare no conflict of interest.

\section{References}

1. Guillard, V.; Gaucel, S.; Fornaciari, C.; Angellier-Coussy, H.; Buche, P.; Gontard, N. The next generation of sustainable food packaging to preserve our environment in a circular economy context. Front. Nutr. 2018, 5. [CrossRef] [PubMed]

2. Jurgilevich, A.; Birge, T.; Kentala-Lehtonen, J.; Korhonen-Kurki, K.; Pietikäinen, J.; Saikku, L.; Schösler, H. Transition towards circular economy in the food system. Sustainability 2016, 8, 69. [CrossRef]

3. Ramesh, M. Flax (Linum usitatissimum L.) fibre reinforced polymer composite materials: A review on preparation, properties and prospects. Prog. Mater. Sci. 2019, 102, 109-166. [CrossRef] 
4. Agüero, A.; Lascano, D.; Garcia-Sanoguera, D.; Fenollar, O.; Torres-Giner, S. Valorization of linen processing by-products for the development of injection-molded green composite pieces of polylactide with improved performance. Sustainability 2020, 12, 652. [CrossRef]

5. Melendez-Rodriguez, B.; Torres-Giner, S.; Aldureid, A.; Cabedo, L.; Lagaron, J.M. Reactive melt mixing of poly(3-hydroxybutyrate)/rice husk flour composites with purified biosustainably produced poly(3-hydroxybutyrate-co-3-hydroxyvalerate). Materials 2019, 12, 2152. [CrossRef]

6. Jothibasu, S.; Mohanamurugan, S.; Vijay, R.; Lenin Singaravelu, D.; Vinod, A.; Sanjay, M.R. Investigation on the mechanical behavior of areca sheath fibers/jute fibers/glass fabrics reinforced hybrid composite for light weight applications. J. Ind. Text. 2018, 49, 1036-1060. [CrossRef]

7. Kumaran, P.; Mohanamurugan, S.; Madhu, S.; Vijay, R.; Lenin Singaravelu, D.; Vinod, A.; Sanjay, M.R.; Siengchin, S. Investigation on thermo-mechanical characteristics of treated/untreated Portunus sanguinolentus shell powder-based jute fabrics reinforced epoxy composites. J. Ind. Text. 2019. [CrossRef]

8. Quiles-Carrillo, L.; Montanes, N.; Garcia-Garcia, D.; Carbonell-Verdu, A.; Balart, R.; Torres-Giner, S. Effect of different compatibilizers on injection-molded green composite pieces based on polylactide filled with almond shell flour. Compos. Part B Eng. 2018, 147, 76-85. [CrossRef]

9. Quiles-Carrillo, L.; Montanes, N.; Sammon, C.; Balart, R.; Torres-Giner, S. Compatibilization of highly sustainable polylactide/almond shell flour composites by reactive extrusion with maleinized linseed oil. Ind. Crops Prod. 2018, 111, 878-888. [CrossRef]

10. Montava-Jordà, S.; Quiles-Carrillo, L.; Richart, N.; Torres-Giner, S.; Montanes, N. Enhanced interfacial adhesion of polylactide/poly( $\varepsilon$-caprolactone)/walnut shell flour composites by reactive extrusion with maleinized linseed oil. Polymers 2019, 11, 758. [CrossRef]

11. Quiles-Carrillo, L.; Montanes, N.; Lagaron, J.M.; Balart, R.; Torres-Giner, S. On the use of acrylated epoxidized soybean oil as a reactive compatibilizer in injection-molded compostable pieces consisting of polylactide filled with orange peel flour. Polym. Int. 2018, 67, 1341-1351. [CrossRef]

12. Torres-Giner, S.; Hilliou, L.; Melendez-Rodriguez, B.; Figueroa-Lopez, K.J.; Madalena, D.; Cabedo, L.; Covas, J.A.; Vicente, A.A.; Lagaron, J.M. Melt processability, characterization, and antibacterial activity of compression-molded green composite sheets made of poly(3-hydroxybutyrate-co-3-hydroxyvalerate) reinforced with coconut fibers impregnated with oregano essential oil. Food Packag. Shelf Life 2018, 17, 39-49. [CrossRef]

13. Chaitanya, S.; Singh, I. Processing of PLA/sisal fiber biocomposites using direct- and extrusion-injection molding. Mater. Manuf. Process. 2017, 32, 468-474. [CrossRef]

14. Thyavihalli Girijappa, Y.G.; Mavinkere Rangappa, S.; Parameswaranpillai, J.; Siengchin, S. Natural fibers as sustainable and renewable resource for development of eco-friendly composites: A comprehensive review. Front. Mater. 2019, 6. [CrossRef]

15. Ramesh, M.; Deepa, C.; Kumar, L.R.; Sanjay, M.R.; Siengchin, S. Life-cycle and environmental impact assessments on processing of plant fibres and its bio-composites: A critical review. J. Ind. Text. 2020. [CrossRef]

16. Adekomaya, O.; Jamiru, T.; Sadiku, R.; Huan, Z. A review on the sustainability of natural fiber in matrix reinforcement - A practical perspective. J. Reinf. Plast. Compos. 2015, 35, 3-7. [CrossRef]

17. Agüero, Á.; Garcia-Sanoguera, D.; Lascano, D.; Rojas-Lema, S.; Ivorra-Martinez, J.; Fenollar, O.; Torres-Giner, S. Evaluation of different compatibilization strategies to improve the performance of injection-molded green composite pieces made of polylactide reinforced with short flaxseed fibers. Polymers 2020, 12, 821. [CrossRef]

18. Lachenmeier, D.W.; Teipel, J.; Scharinger, A.; Kuballa, T.; Walch, S.G.; Grosch, F.; Bunzel, M.; Okaru, A.O.; Schwarz, S. Fully automated identification of coffee species and simultaneous quantification of furfuryl alcohol using NMR spectroscopy. J. AOAC Int. 2020, 103, 306-314. [CrossRef]

19. Murthy, P.S.; Madhava Naidu, M. Sustainable management of coffee industry by-products and value addition-A review. Resour. Conserv. Recycl. 2012, 66, 45-58. [CrossRef]

20. Janissen, B.; Huynh, T. Chemical composition and value-adding applications of coffee industry by-products: A review. Resour. Conserv. Recycl. 2018, 128, 110-117. [CrossRef]

21. Mussatto, S.I.; Machado, E.M.S.; Martins, S.; Teixeira, J.A. Production, composition, and application of coffee and its industrial residues. Food Bioprocess Technol. 2011, 4, 661. [CrossRef] 
22. Klingel, T.; Kremer, J.I.; Gottstein, V.; Rajcic de Rezende, T.; Schwarz, S.; Lachenmeier, D.W. A review of coffee by-products including leaf, flower, cherry, husk, silver skin, and spent grounds as novel foods within the European Union. Foods 2020, 9, 665. [CrossRef] [PubMed]

23. Roussos, S.; de Los Angeles Aquiáhuatl, M.; Del Refugio Trejo-Hernández, M.; Gaime Perraud, I.; Favela, E.; Ramakrishna, M.; Raimbault, M.; Viniegra-González, G. Biotechnological management of coffee pulp—isolation, screening, characterization, selection of caffeine-degrading fungi and natural microflora present in coffee pulp and husk. Appl. Microbiol. Biotechnol. 1995, 42, 756-762. [CrossRef]

24. Narita, Y.; Inouye, K. Review on utilization and composition of coffee silverskin. Food Res. Int. 2014, 61, 16-22. [CrossRef]

25. Woldesenbet, A.G.; Woldeyes, B.; Chandravanshi, B.S. Bio-ethanol production from wet coffee processing waste in Ethiopia. SpringerPlus 2016, 5, 1903. [CrossRef]

26. Mendoza Martinez, C.L.; Alves Rocha, E.P.; Oliveira Carneiro, A.d.C.; Borges Gomes, F.J.; Ribas Batalha, L.A.; Vakkilainen, E.; Cardoso, M. Characterization of residual biomasses from the coffee production chain and assessment the potential for energy purposes. Biomass Bioenergy 2019, 120, 68-76. [CrossRef]

27. Hachicha, R.; Rekik, O.; Hachicha, S.; Ferchichi, M.; Woodward, S.; Moncef, N.; Cegarra, J.; Mechichi, T. Co-composting of spent coffee ground with olive mill wastewater sludge and poultry manure and effect of Trametes versicolor inoculation on the compost maturity. Chemosphere 2012, 88, 677-682. [CrossRef]

28. Ballesteros, L.F.; Teixeira, J.A.; Mussatto, S.I. Chemical, functional, and structural properties of spent coffee grounds and coffee silverskin. Food Bioprocess Technol. 2014, 7, 3493-3503. [CrossRef]

29. Murthy, P.S.; Naidu, M.M. Production and application of xylanase from penicillium sp. utilizing coffee by-products. Food Bioprocess Technol. 2012, 5, 657-664. [CrossRef]

30. Low, J.H.; Rahman, W.A.W.A.; Jamaluddin, J. Structural elucidation of tannins of spent coffee grounds by CP-MAS 13C NMR and MALDI-TOF MS. Ind. Crops Prod. 2015, 69, 456-461. [CrossRef]

31. Franklin, G.; Dias, A.C.P. Chlorogenic acid participates in the regulation of shoot, root and root hair development in Hypericum perforatum. Plant Physiol. Biochem. 2011, 49, 835-842. [CrossRef]

32. García, A.; Gandini, A.; Labidi, J.; Belgacem, N.; Bras, J. Industrial and crop wastes: A new source for nanocellulose biorefinery. Ind. Crops Prod. 2016, 93, 26-38. [CrossRef]

33. Moustafa, H.; Guizani, C.; Dupont, C.; Martin, V.; Jeguirim, M.; Dufresne, A. Utilization of torrefied coffee grounds as reinforcing agent to produce high-quality biodegradable pbat composites for food packaging applications. ACS Sustain. Chem. Eng. 2017, 5, 1906-1916. [CrossRef]

34. Wang, Z.; Dadi Bekele, L.; Qiu, Y.; Dai, Y.; Zhu, S.; Sarsaiya, S.; Chen, J. Preparation and characterization of coffee hull fiber for reinforcing application in thermoplastic composites. Bioengineered 2019, 10, 397-408. [CrossRef] [PubMed]

35. García-García, D.; Carbonell, A.; Samper, M.D.; García-Sanoguera, D.; Balart, R. Green composites based on polypropylene matrix and hydrophobized spend coffee ground (SCG) powder. Compos. Part B Eng. 2015, 78, 256-265. [CrossRef]

36. Franca, A.S.; Oliveira, L.S. Coffee processing solid wastes: Current uses and future perspectives. In Agricultural Wastes; Nova Science Publishers, Inc.: Hauppauge, NY, USA, 2009; pp. 155-190.

37. Gouvea, B.M.; Torres, C.; Franca, A.S.; Oliveira, L.S.; Oliveira, E.S. Feasibility of ethanol production from coffee husks. Biotechnol. Lett. 2009, 31, 1315-1319. [CrossRef]

38. Arias, B.; Pevida, C.; Fermoso, J.; Plaza, M.G.; Rubiera, F.; Pis, J.J. Influence of torrefaction on the grindability and reactivity of woody biomass. Fuel Process. Technol. 2008, 89, 169-175. [CrossRef]

39. Chen, W.-H.; Peng, J.; Bi, X.T. A state-of-the-art review of biomass torrefaction, densification and applications. Renew. Sustain. Energy Rev. 2015, 44, 847-866. [CrossRef]

40. Ribeiro, J.M.C.; Godina, R.; Matias, J.C.d.O.; Nunes, L.J.R. Future perspectives of biomass torrefaction: Review of the current state-of-the-art and research development. Sustainability 2018, 10, 2323. [CrossRef]

41. Hamad, K.; Kaseem, M.; Ayyoob, M.; Joo, J.; Deri, F. Polylactic acid blends: The future of green, light and tough. Prog. Polym. Sci. 2018, 85, 83-127. [CrossRef]

42. Quiles-Carrillo, L.; Montanes, N.; Pineiro, F.; Jorda-Vilaplana, A.; Torres-Giner, S. Ductility and toughness improvement of injection-molded compostable pieces of polylactide by melt blending with poly ( $\varepsilon$-caprolactone) and thermoplastic starch. Materials 2018, 11, 2138. [CrossRef]

43. Chen, Y.; Geever, L.M.; Killion, J.A.; Lyons, J.G.; Higginbotham, C.L.; Devine, D.M. Review of multifarious applications of poly(lactic acid). Polym. Plast. Technol. Eng. 2016, 55, 1057-1075. [CrossRef] 
44. Risyon, N.P.; Othman, S.H.; Basha, R.K.; Talib, R.A. Characterization of polylactic acid/halloysite nanotubes bionanocomposite films for food packaging. Food Packag. Shelf Life 2020, 23, 100450. [CrossRef]

45. Cardoso, R.M.; Silva, P.R.L.; Lima, A.P.; Rocha, D.P.; Oliveira, T.C.; do Prado, T.M.; Fava, E.L.; Fatibello-Filho, O.; Richter, E.M.; Muñoz, R.A.A. 3D-Printed graphene/polylactic acid electrode for bioanalysis: Biosensing of glucose and simultaneous determination of uric acid and nitrite in biological fluids. Sens. Actuators B Chem. 2020, 307, 127621. [CrossRef]

46. Harris, A.M.; Lee, E.C. Heat and humidity performance of injection molded PLA for durable applications. J. Appl. Polym. Sci. 2010, 115, 1380-1389. [CrossRef]

47. Kumar, S.; Bhatnagar, N.; Ghosh, A.K. Effect of enantiomeric monomeric unit ratio on thermal and mechanical properties of poly(lactide). Polym. Bull. 2016, 73, 2087-2104. [CrossRef]

48. Rocha, D.B.; de Souza, A.G.; Szostak, M.; Rosa, D.d.S. Polylactic acid/Lignocellulosic residue composites compatibilized through a starch coating. Polym. Compos. 2020. [CrossRef]

49. Siakeng, R.; Jawaid, M.; Asim, M.; Siengchin, S. Accelerated weathering and soil burial effect on biodegradability, colour and textureof coir/pineapple leaf fibres/pla biocomposites. Polymers 2020, 12, 458. [CrossRef] [PubMed]

50. Rojas-Lema, S.; Quiles-Carrillo, L.; Garcia-Garcia, D.; Melendez-Rodriguez, B.; Balart, R.; Torres-Giner, S. Tailoring the properties of thermo-compressed polylactide films for food packaging applications by individual and combined additions of lactic acid oligomer and halloysite nanotubes. Molecules 2020, 25, 1976. [CrossRef] [PubMed]

51. Torres-Giner, S.; Martinez-Abad, A.; Gimeno-Alcañiz, J.V.; Ocio, M.J.; Lagaron, J.M. Controlled delivery of gentamicin antibiotic from bioactive electrospun polylactide-based ultrathin fibers. Adv. Eng. Mater. 2012, 14, B112-B122. [CrossRef]

52. Huang, L.; Mu, B.; Yi, X.; Li, S.; Wang, Q. Sustainable use of coffee husks for reinforcing polyethylene composites. J. Polym. Environ. 2018, 26, 48-58. [CrossRef]

53. Berthet, M.A.; Commandré, J.M.; Rouau, X.; Gontard, N.; Angellier-Coussy, H. Torrefaction treatment of lignocellulosic fibres for improving fibre/matrix adhesion in a biocomposite. Mater. Des. 2016, 92, 223-232. [CrossRef]

54. Lessa, E.F.; Nunes, M.L.; Fajardo, A.R. Chitosan/waste coffee-grounds composite: An efficient and eco-friendly adsorbent for removal of pharmaceutical contaminants from water. Carbohydr. Polym. 2018, 189, 257-266. [CrossRef]

55. Suaduang, N.; Ross, S.; Ross, G.M.; Pratumshat, S.; Mahasaranon, S. Effect of spent coffee grounds filler on the physical and mechanical properties of poly(lactic acid) bio-composite films. Mater. Today Proc. 2019, 17, 2104-2110. [CrossRef]

56. Wu, C.-S. Renewable resource-based green composites of surface-treated spent coffee grounds and polylactide: Characterisation and biodegradability. Polym. Degrad. Stab. 2015, 121, 51-59. [CrossRef]

57. Tsuji, H.; Kawashima, Y.; Takikawa, H.; Tanaka, S. Poly(L-lactide)/nano-structured carbon composites: Conductivity, thermal properties, crystallization, and biodegradation. Polymer 2007, 48, 4213-4225. [CrossRef]

58. Dominici, F.; García García, D.; Fombuena, V.; Luzi, F.; Puglia, D.; Torre, L.; Balart, R. Bio-polyethylene-based composites reinforced with alkali and palmitoyl chloride-treated coffee silverskin. Molecules 2019, 24, 3113. [CrossRef]

59. Songtipya, L.; Limchu, T.; Phuttharak, S.; Songtipya, P.; Kalkornsurapranee, E. Poly(lactic acid)-based composites incorporated with spent coffee ground and tea leave for food packaging application: A waste to wealth. In Proceedings of the IOP Conference Series: Materials Science and Engineering, Bali, Indonesia, 30 October-2 November 2018.

60. Balart, J.F.; García-Sanoguera, D.; Balart, R.; Boronat, T.; Sánchez-Nacher, L. Manufacturing and properties of biobased thermoplastic composites from poly(lactid acid) and hazelnut shell wastes. Polym. Compos. 2018, 39, 848-857. [CrossRef]

61. Wang, L.; Qiu, J.; Sakai, E.; Wei, X. The relationship between microstructure and mechanical properties of carbon nanotubes/polylactic acid nanocomposites prepared by twin-screw extrusion. Compos. Part A Appl. Sci. Manuf. 2016, 89, 18-25. [CrossRef]

62. Arbelaiz, A.; Txueka, U.; Mezo, I.; Orue, A. Biocomposites based on poly(lactic acid) matrix and reinforced with lignocellulosic fibers: The effect of fiber type and matrix modification. J. Nat. Fibers 2020, 1-14. [CrossRef] 
63. Johari, A.P.; Mohanty, S.; Kurmvanshi, S.K.; Nayak, S.K. Influence of different treated cellulose fibers on the mechanical and thermal properties of poly(lactic acid). ACS Sustain. Chem. Eng. 2016, 4, 1619-1629. [CrossRef]

64. Cataldo, V.A.; Cavallaro, G.; Lazzara, G.; Milioto, S.; Parisi, F. Coffee grounds as filler for pectin: Green composites with competitive performances dependent on the UV irradiation. Carbohydr. Polym. 2017, 170, 198-205. [CrossRef]

65. Arrigo, R.; Jagdale, P.; Bartoli, M.; Tagliaferro, A.; Malucelli, G. Structure-property relationships in polyethylene-based composites filled with biochar derived from waste coffee grounds. Polymers 2019, 11, 1336. [CrossRef]

66. Cisneros-López, E.O.; Pérez-Fonseca, A.A.; González-García, Y.; Ramírez-Arreola, D.E.; González-Núñez, R.; Rodrigue, D.; Robledo-Ortíz, J.R. Polylactic acid-agave fiber biocomposites produced by rotational molding: A comparative study with compression molding. Adv. Polym. Technol. 2018, 37, 2528-2540. [CrossRef]

67. Sonseca, A.; Madani, S.; Rodríguez, G.; Hevilla, V.; Echeverría, C.; Fernández-García, M.; Muñoz-Bonilla, A.; Charef, N.; López, D. Multifunctional PLA blends containing chitosan mediated silver nanoparticles: Thermal, mechanical, antibacterial, and degradation properties. Nanomaterials 2020, 10, 22. [CrossRef]

68. Yaacab, N.D.; Ismail, H.; Ting, S.S. Potential use of paddy straw as filler in poly lactic acid/paddy straw powder biocomposite: Thermal and thermal properties. Procedia Chem. 2016, 19, 757-762. [CrossRef]

69. Cai, H.; Ba, Z.; Yang, K.; Zhang, Q.; Zhao, K.; Gu, S. Pyrolysis characteristics of typical biomass thermoplastic composites. Results Phys. 2017, 7, 3230-3235. [CrossRef]

70. De Brito, E.B.; Tienne, L.G.P.; Cordeiro, S.B.; Marques, M.d.F.V. Development of polypropylene composites with green coffee cake fibers subjected to water vapor explosion. Waste Biomass Valorization 2020. [CrossRef]

71. Totaro, G.; Sisti, L.; Fiorini, M.; Lancellotti, I.; Andreola, F.N.; Saccani, A. Formulation of green particulate composites from pla and pbs matrix and wastes deriving from the coffee production. J. Polym. Environ. 2019, 27, 1488-1496. [CrossRef]

72. Sarasini, F.; Tirillò, J.; Zuorro, A.; Maffei, G.; Lavecchia, R.; Puglia, D.; Dominici, F.; Luzi, F.; Valente, T.; Torre, L. Recycling coffee silverskin in sustainable composites based on a poly(butylene adipate-co-terephthalate)/ poly(3-hydroxybutyrate-co-3-hydroxyvalerate) matrix. Ind. Crops Prod. 2018, 118, 311-320. [CrossRef]

73. Bouzidi, F.; Guessoum, M.; Fois, M.; Haddaoui, N. Viscoelastic, thermo-mechanical and environmental properties of composites based on polypropylene/poly(lactic acid) blend and copper modified nanoclay. J. Adhes. Sci. Technol. 2018, 32, 496-515. [CrossRef]

74. Kodama, M.; Karino, I. Effects of polar groups of polymer matrix on reinforcement-matrix interaction in kevlar fiber-reinforced composites. J. Appl. Polym. Sci. 1986, 32, 5057-5069. [CrossRef]

75. Torres-Giner, S.; Montanes, N.; Fenollar, O.; García-Sanoguera, D.; Balart, R. Development and optimization of renewable vinyl plastisol/wood flour composites exposed to ultraviolet radiation. Mater. Des. 2016, 108, 648-658. [CrossRef]

(C) 2020 by the authors. Licensee MDPI, Basel, Switzerland. This article is an open access article distributed under the terms and conditions of the Creative Commons Attribution (CC BY) license (http://creativecommons.org/licenses/by/4.0/). 